\title{
Barriers to The Utilization of Cardiovascular Risk Prediction Tools as Perceived by Primary Health Care and Family Physicians
}

\author{
Mirella Youssef Tawfik*, Ayman Ekram Fahim*, Mosleh Abdelrahman Ismail ${ }^{* *}$ \\ and Shaimaa Ateya Moussa* \\ Departments of Community Medicine*, and Family Medicine**, Suez Canal University, \\ Ismailia, Egypt
}

\begin{abstract}
Background: Mortality from cardiovascular diseases was ranked the first cause of death in Egypt, accounting for $46 \%$ of total deaths. Although the use of cardiovascular risk prediction tools (CVRPT) to identify those at higher risk was proven to be a costeffective strategy, these tools remain underutilized in clinical practice. Objective: To investigate the barriers to the utilization of CVRPT as perceived by primary health care and family physicians. Subjects and Methods: A cross sectional study was conducted in 25 primary health care and family medicine units in three Egyptian cities using an adapted questionnaire. Results: One hundred and seventy six (176) eligible physicians from a recruited sample of 230 (response rate=76\%) participated in the study. About $81 \%$ of all physicians rarely or never use CVRPT. Most often stated barriers to use CVRPT are: distrust in stakeholders' interest $(88.7 \%)$, patients' non-compliance due to inability to afford requested investigations $(83 \%)$, and the imperfection of using single score in measuring patient's global cardiovascular risk (82\%). Among different questionnaire domains, the "distrust in CVRPT validity" was found to be the most important domain influencing the utilization of CVRPT ( $\mathrm{p}=0.045$ ), and among all questionnaire items, the "Distrust in stakeholders' interest", and "a single score doesn't take into account the complex situation of the patient" were found to be the most important indicators influencing CVRPT utilization by logistic regression analysis. Forty seven percent (47\%) reported that the health care system does not support the use of CVRPT due to economic reasons, and 36\% reported the need for an easy and cost-effective tool. Conclusion: Distrust in the validity and comprehensiveness of CVRPT, distrust in stakeholders, lack of time, lack of physician knowledge and training, and economic reasons were the most important barriers against the utilization of CVRPT. Further studies are needed for examining the effect of global CVD calculation on actual patient outcomes. Communication among CVRPT stakeholders and health care policy makers in Egypt, adopting a simple, cost effective CVRPT, and physician training were suggested to promote the utilization of CVR scores in clinical practice.
\end{abstract}

\section{Introduction}

Cardiovascular disease (CVD) is the cause of death of more than 500 per 100,000 population in Egypt. It was ranked the first cause of death, and accounting for $46 \%$ of total deaths in all ages and both sexes ${ }^{(1)}$. Moreover, CVD events were experienced at a younger age, and death occurs much earlier in our country compared to 'high income' countries $^{(2)}$. The challenge in Egypt, like 
many other developing economies, is that the expected increase in risk factors and incidence rates of CVD are rapid enough to outpace the development of health care networks, human resources, and the infrastructure needed to manage such an important chronic disease ${ }^{(3)}$. Effective strategies for the prevention and control of CVD in Egypt are imperative.

There are no national guidelines for the prevention and management of CVD risk factors in Egypt and Egypt follows the European guidelines for the management of cardiovascular diseases. Because atherosclerosis underlying most CVD is rarely the result of a single risk factor, considering management guidelines for a single risk factor may result in either overtreatment or undertreatment. These considerations have led the authors of all current guidelines to recommend tools for estimation of individualized global absolute cardiovascular risk (CVR) through evaluating combined risk factor effects, the so called "the cardiovascular risk prediction tools (CVRPT)"(4). The key domains of CVRPT include: nonmodifiable risk factors domain (age, sex), modifiable risk factors domain (smoking status, systolic blood pressure, total cholesterol, high density lipoprotein cholesterol, and sometimes low density lipoprotein), and in some risk tools a medical history domain (the presence or absence of diabetes) $)^{(5)}$.

Primary health care physicians play an important role for individual directed primary prevention of CVD during patient consultation ${ }^{(4)}$. In developing countries, where primary care centers have scarce resources, physicians should follow high risk strategies aiming for the identification and treatment of those at higher risk and avoidance of harm in those who are not ${ }^{(6)}$. As risk factors often cluster together and the majority of cardiovascular events occur in individuals with modest elevations of several risk factors more than in individuals with marked elevation of a single risk factor, focusing on cholesterol or blood pressure levels separately to identify high-risk individuals is not cost-effective. A more cost-effective approach is to base treatment decisions on estimation of each individual's risk of a cardiovascular event in the foreseeable future through $\operatorname{CVRPT}^{(7)}$.

For research purposes many authors have used CVRPT for estimating CVR in primary health care settings of developed and developing countries ${ }^{(8-13)}$, but practically these tools remain underutilized in clinical settings ${ }^{(14)}$. Studies in developed countries have shown that physicians rarely apply CVRPT $^{(15,16)}$, and in developing countries there are complex challenges for application of CVRPT ${ }^{(17)}$. Little is known about the application of these tools in Egypt. Results concluded from similar studies performed in the developed world ${ }^{(18-20)}$ may not be appropriate for use in our country. The objectives of this study were to assess the use of CVRPT and to investigate barriers to the application of these tools as perceived by primary health care and family physicians.

\section{Subjects and methods}

\section{Subjects:}

Twenty experts (20) in general practice, family medicine, internal medicine and cardiology (5 from each) affiliated with either the Ministry of Health or the Faculty of Medicine-Suez Canal University, participated in the process of questionnaire development. 
Two hundred and thirty (230) physicians (a sample of 170 physicians was estimated according to the prevalence of utilization of CVRPT in a previous study $^{(21)}$ and a drop out of $35 \%$ was added for calculation) working in primary health care centers and family medicine units (16 and 9 respectively) of 3 Egyptian cities (Port Said, Ismailia, and Suez) were randomly selected for recruiting in a cross sectional study. All eligible physicians in a position to initiate cardiovascular drug treatment (general practitioners, family physicians, general internal medicine physicians, and cardiologists) were included. Questionnaires were distributed at the beginning of a work day and collected after the end of the work day, between July 2012 and February 2013. Responses for the participated physicians were used in determining the questionnaire reliability and validity and to determine the barriers for not applying CVRPT.

\section{Methods}

\section{Questionnaire development}

A previously developed unevaluated tool for identifying barriers for the application of CVRPT ${ }^{(16)}$ was proposed for two round modified Delphi process $^{(22)}$. The tool contained 19 questions covering the dimensions of three different barriers: lack of knowledge, distrust, and practicability, in addition to one question about the role of CVRPT for decision making in practice, and one open ended question about other reasons for never or rarely using CVRPT.

Questions representing these domains were reviewed and reformatted, scaled by using five point Likert scale ranging from the strong disagreement (1) to the strong agreement (5), and distributed to the panel of experts, who were asked to respond anonymously, to suggest modifications, and to add other suggested questions. Questions with response median of 3.5 or higher were retained. Analysis was repeated in the 2nd round step of the Delphi process and retained questions were scaled by 3 point Likert scale using "agree all the time, agree most of the time, and do not agree"; or "agree, disagree, and not sure" according to the linguistic requirement of each question.

A question about the frequency of using prediction rules in three categories ("often" defined as at least once a week; "rarely" defined as less than once a month; and "never") was added. Questions asking about physicians' characteristics were finally added to the developed questionnaire, and a short introduction explaining the context of the study was attached.

\section{Ethical consideration:}

Permission for data collection was obtained from Directorate of Health and from the Ethics Committee of the Faculty of Medicine, Suez Canal University. Physicians were informed verbally about the purpose of the study before participation, and they were informed that all responses would be treated anonymously. Questionnaires were distributed among recruited physicians and consent was implied by the return of completed ones.

\section{Statistical analysis:}

Data were analyzed using SPSS 17.0 (SPSS Inc., Chicago, IL, USA). Frequency and percentages were computed for qualitative data; medians, means and standard deviations were calculated for quantitative data. Fisher's exact/Chi-square was used to test for the 
statistical significance of qualitative variables. The ordinal scale of the questionnaire was converted to a numerical one $(3=$ agree all of the time, $2=$ agree most of the time $\&$ not sure, and 1 for don't agree), and scores obtained were used for determining the questionnaire's reliability and validity, and for measuring domain means. Item total correlation was used to test for total questionnaire reliability, and multiple correlation was used to test for initial validity of each domain on the questionnaire. ANOVA was used for testing statistical significance among means of domains and utilization of CVRPT. Conditional logistic regression was used to determine the questionnaire's indicators of nonutilizing CVRPT.

\section{Results: \\ Questionnaire development}

By the end of the $1^{\text {st }}$ step Delphi process, questions in the knowledge domain were reversed in ranking, and the question about "the usefulness of the CVRPT for prevention" was split into two questions: "risk assessment is of no use if not accompanied by preventive measures", and "patients' cardiac risk information will not guarantee for their compliance and thus for prevention of cardiac risks". Only two questions were omitted for having a response median less than 3.5: the question about "ethical concerns for not using CVRPT" (median=2.5) (panelists explained that no ethical reasons could prevent the application of CVRPT), and the question about "CVRPT for not being helpful for decision making in practice" (median=2), (panelists commented that it is a vague question, and that it is already explained in other domains). An open question about "three major categories of major risk factors" was added in the knowledge domain. Almost all questions were modified for linguistic requirements. Questions of the first step Delphi process were all retained by the end of the $2^{\text {nd }}$ step in the process.

\section{Study results:}

One hundred and seventy six (176) physicians, from a total number of 230 , completed the questionnaire (response rate $=76 \%$ ). Physicians' demographic characteristics were shown in Table I. Ninety nine $(56 \%)$ of participated physicians reported "often/rarely" using CVRPT in their practice, among them $67 \%$ know "the difference between CVRPT and guidelines" and "which CVRPT to choose" in their practice. Family physicians reported using CVRPT more than physicians in other specialties $(75 \%)$, and this was found to be statistically significant. Using CVRPT was higher in younger physicians (57\%), in females $(61 \%)$, in physicians with $\geq 10$ years of experience, and in those who obtained a diploma degree, compared to other physician subgroups for each respective categorical variable, and these differences was found to be statistically non-significant (Table I). Among those who reported "often/rarely" use CVRPT, the WHO CVR score was the most commonly used, followed by the Framingham and the British risk score $(73 \%, 52 \%$, and $27 \%)$ with some physicians using more than one risk score. Physicians have reported 8 CVR factors: hypertension, diabetes, smoking, lipids, occupation, obesity, stress, and cholesterol $(61 \%, 53 \%, 47 \%$, $41 \%, 33 \%, 21 \%, 11 \%$, and $8 \%$ respectively). 
The highest percentage of agreement by physicians on barriers against application of CVRPT was for "which stakeholders were involved in the development of these tools" (89\%), "tools may depend on investigations that patients could not afford" (83\%), "a single risk score does not take into account the complex situation of the patient" $(82 \%)$, and "risk assessment is of no use if not accompanied by preventive measures" (81\%). Total Questionnaire reliability has a cronbach's coefficient alpha $(\mathrm{CC} \alpha)$ of .78 , and the initial validities of domains have correlation coefficients that range from .331 (Distrust in stakeholders), to .586 (Distrust in the validity of CVRPT) (Table II).

Four barriers have been found to have a statistically significant association $(\mathrm{P}<0.05)$ with physician non-utilization of CVRPT. These are: (1) "a single risk score does not take into account the complex situation of the patient", "CVRPT could not be applied to all patients' groups", (3) "you don't know which stakeholders were involved in the development of these tools", (4) "application of CVRPT is time consuming". When the means of the domain scores were compared using ANOVA, the "distrust in the validity of CVRPT" was found to be the domain that has a statistically significant difference between its mean and other domain means $(\mathrm{P}<0.05)$ (Table III). With conditional logistic regression analysis two barriers were found to be the most important ones indicating nonutilization of CVRPT $(\mathrm{P}<0.05)$, these are: "a single risk score does not take into account the complex situation of the patient" and "you don't know which stakeholders were involved in the development of these tools" (Table IV).
Ninety physicians (response rate $=51 \%$ ) responded on the open ended question about other reasons for never or rarely using CVRPT. Forty seven percent $(47 \%)$ stated that the health care system does not support the use of CVRPT due to economic reasons, $36 \%$ reported the need for an easy cost-effective tool, and $34 \%$ reported the lack of physician knowledge and training.

\section{Discussion}

Cardiovascular risk estimates can theoretically be used to raise population awareness of CVD, to communicate knowledge about that risk to individuals and subgroups, and to motivate adherence to recommended lifestyle changes or therapies ${ }^{(6)}$. The challenge is to encourage the implementation of CVRPT in day-to-day risk evaluation and management ${ }^{(23)}$. Despite the recommended use of risk scores, survey results from different developed countries indicate that most physicians do not routinely use them in general practice $^{(20,24-27)}$. In our country, a related study was conducted for that purpose but was too methodologically limited to draw a significant conclusion, and lacks in-depth investigations of barriers to CVRPT use ${ }^{(28)}$. Few studies have investigated the effectiveness of using CVRPT in primary health care settings of developing countries ${ }^{(8,9)}$, and one study has explained that complex challenges faces the application of these tools in low income countries mainly due to lack of basic infrastructure facilities to support resource intensive CVRPT $^{(17)}$.

In our study, only $56 \%$ of the participating physicians reported often (19\%) and rarely (37\%) using CVRPT; this was in agreement with other studies 
which reported the "usually/always" use $^{(27)}$, the "often/always" use ${ }^{(25)}$, and the routine use ${ }^{(26)}$ of CVRPT to be $23 \%$, $41 \%$, and $54 \%$ respectively. A survey conducted in different countries all over the world revealed that $48 \%$ of physicians regularly used guidelines or risk calculators to determine total risk ${ }^{(29)}$. About $67 \%$ of participating physicians who reported using the CVRPT stated that they know the differences between risk scores and guidelines, and know which score to choose. In related researches, "guidelines" were used as a metaphor for "cardiovascular guidelines for individual risk factors". On the other hand, "CVR score" is defined as an integrated CVD risk assessment approach that measures CVR on the basis of the combined effect of multiple risk factors. As individuals tend to develop clusters of risk factors and the cumulative effects of multiple factors may be additive or synergistic, assessment of CVR on the basis of the combined effect of multiple risk factors is more accurate than the application of several separate guidelines for CVR factors $^{(30)}$.

In our study $33 \%$ of those who use the risk scores apply them with uncertainty regarding their definition. This was in consistent with a previous study which stated that only $60 \%$ of primary care physicians were aware about the definition of CVR scores and that this influenced their utilization in practice ${ }^{(31)}$. Lack of awareness about the definition of CVR scores among those who are utilizing them could not only influence the communication of this risk with patients, but could also affect patient adherence to treatment strategies ${ }^{(32)}$.

Thirty three percent of physicians who reported using the CVRPT scores don't know which to choose in their practice.
Many CVR scores are in existence ${ }^{(33-40)}$, but they differ considerably in terms of population, predictors, and outcomes, which may not match those used by clinicians $^{(41)}$. This could explain the physicians' confusion regarding which CVRPT to choose for their patients. Whichever risk equation they choose, clinicians should know which outcomes are predicted. As the outcomes predicted differ significantly (cerebro-vascular events, fatal cardiovascular events, and 'soft' outcomes such as angina), the risk scores are not interchangeable, and the use of the unsuitable one could lead to under or over estimation of risk ${ }^{(41)}$.

In our study, the utilization of CVRPT among physicians as well as their knowledge about these tools was found to be more among younger physicians. This could be because younger physicians are more likely to adhere to guidelines than more experienced physicians $^{(24)}$, and that it may be more difficult for older physicians to overcome previous practice inertia ${ }^{(42)}$. A previous study suggested that adherence to guidelines could be due to other reasons that are not related to physician age, including lack of knowledge of the guidelines, disagreement with the evidence, and lack of expectations that adherence will result in better patient outcomes $^{(43)}$.

Family physicians showed a higher percentage of CVRPT utilization $(75 \%)$ compared with general practitioners (54\%) and cardiologists (50\%) with statistical significance in differences. This was in agreement with another study which showed that cardiologists were most likely to indicate that CHD risk scoring is not useful in clinical practice, and explained that this could potentially be related to the lower proportion of patients seen for which 
primary prevention (rather than secondary prevention) is of concern ${ }^{(25)}$. Utilization of the tools among those who had been in practice for more than 10 years $(70 \%)$ was more than the utilization among those with lesser years of experience. This was in agreement with previous studies which showed that older physicians are more likely to be aware and incorporate guidelines to practice $^{(25,44)}$. Other studies have shown an inverse relationship between years in practice and awareness and utilization of CVRPT $^{(24,45)}$.

In our study the WHO charts and the Framingham risk score were the most commonly used CVRPT by physicians. Being the first choice of use among Egyptian physicians could be because the WHO charts developed by the World Health Organization/International Society of Hypertension are in formats that exclude lipid measurements, so they are particularly suited to areas in the developing world where access to medical facilities is limited ${ }^{(23,38)}$. The Framingham system was reported to be the best known CVRPT both nationally and internationally and the most commonly used ${ }^{(33)}$.

When physicians were asked to name three major cardiovascular risk factors, it was found that hypertension, diabetes, and smoking were the most frequently reported $(61 \%, 53 \%$, and $47 \%$ respectively). This was in agreement with a related study which showed that smoking status, family history of CVD, blood pressure, $(88 \%, 86 \%$, and $81 \%$ respectively) are the most frequently documented $\mathrm{CV}$ risk factors for physician decision making in practice ${ }^{(28)}$.

The questionnaire showed good internal consistency reliability ${ }^{(46)}(\mathrm{CC} \alpha=.78)$, and moderate to strong strength of correlation $^{(47)}$ ( $\mathrm{R}$ ranges from.331 to
.586). In our study the "distrust in the validity of CVRPT" was the domain that showed a statistical significance, when its mean was compared with the other domain means. This was in consistency with results of other studies ${ }^{(18,48,49)}$. Physicians distrust in the validity of CVRPT could be due to the lack of evidence based data that proves the positive impact of utilizing CVRPT on patient outcomes ${ }^{(25)}$. Further studies for examining the effect of global CVD calculation on actual patient outcomes are needed.

The highest percentage of physician agreement on barriers against application of CVRPT was found to be for four barriers distributed equally in the four domains of the questionnaire, with the highest agreement percentage (89\%) for "which stakeholders were involved in the development of these tools", which was found to be statistically significant using Chi square and to be one of the most important barrier influencing CVRPT utilization. Physician distrust in stakeholders could be due to the lack of communication of CVRPT sponsors with participants and communities through professional meetings or academic programs to ensure the best practice. This lack of communication will foster a climate of distrust in science and implies disinterest or disrespect for participants and communities ${ }^{(50)}$. Further communication is needed among CVRPT stakeholders and health care policy makers in Egypt for guiding evidence based prevention of CVD. Cardiovascular risk prediction tools were developed by many stakeholders' organizations (e.g. European Society of Cardiology, the National Heart Lung and Blood Institute, and the world Health Organization/International Society of Hypertension $)^{(51-53)}$. The only 
stakeholder organization that have taking in consideration the development of formats that suits primary health care settings in developing countries including Egypt is the World Health Organization/International Society of Hypertension $^{(54)}$. This organization has considered the inability of basic infrastructure facilities in low income countries to support the costs of blood lipids investigations needed by other CVRPT $^{(17)}$.

The second ranked important barrier was the high costs of the investigations $(83 \%)$. This was consistent with another study which revealed $80 \%$ of physician agreement about the high costs of required investigations ${ }^{(28)}$. Another study considered non-affordability of investigation costs as the most important barrier against the utilization of these tools ${ }^{(29)}$. Adopting a clear, easy, and simple CVRPT in clinical practice will promote its utilization and will guarantee an effective physician/patient partnership to better patient outcomes.

The third ranked important barrier (82\%) was that "A single score doesn't take into account the complex situation of the patient", which was found to be statistically significant using Chi square and to be one of the most important barrier influencing CVRPT utilization. This was in agreement with a previous study which showed that the opinion of more than half of participating physicians that the single risk score derived from prediction rules will oversimplify the situation of the patient ${ }^{(18)}$. Physician distrust in the comprehensiveness of a single risk score could be due to physician awareness about the absence from the risk calculators of important risk factors such as weight, exercise, family history, and stress $^{(20)}$. The fourth most important barrier $(81 \%)$ was that "risk assessment is of no use if not accompanied by prevention". A previous study has suggested that a better link between risk estimates and lifestyle recommendation would overcome the barriers against CVRPT utilization ${ }^{(31)}$. Another study showed that the poor understanding of how to use CVRPT in clinical management was considered one of the most important barriers against utilization of these tools ${ }^{(55)}$. These findings highlight the need for appropriate information and training of physicians regarding CVR scores, and for creating a better link between risk estimates and lifestyle recommendations.

In our study the barriers "inability to apply CVRPT to all population, and "application is time consuming" were shown to show statistical significance in the difference between users and nonusers. In a related study, the physician perception that risk scores lack accuracy in their patient population was considered as one of the most important barriers against utilization of CVRPT ${ }^{(31)}$. This limitation in the application of CVRPT could be explained by the inappropriateness of applying a tool that was developed in one patient population on another population with a different risk level, ethnic background, or socioeconomic strata, as this may over or underestimate risk in this population ${ }^{(35)}$. Many related researches have reported "time consuming" as a main barrier against CVRPT utilization ${ }^{(20,25,26)}$. It has been shown previously that one of the main barriers to delivery of preventive health services in primary care is lack of time ${ }^{(56)}$. While lack of time during primary care patient visits is certainly a valid concern, there are many tools available that offer very quick and 
accurate calculation of a patient $\mathrm{CHD}$ risk score ${ }^{(57)}$

Forty seven percent of respondents to the open ended question about other reasons for non-utilization of CVRPT stated that the health care system doesn't support the use of CVRPT due to economic reasons, $36 \%$ reported the need for an easy cost-effective tool, and $34 \%$ reported the lack of physician knowledge and training. Other studies revealed similar reasons but with different proportions $^{(17,28,58)}$.

\section{Conclusion and recommendations:}

Distrust in the validity and comprehensiveness of CVRPT, distrust in stakeholders, lack of time, lack of physician knowledge and training, and economic reasons were the most important barriers against the utilization of CVRPT. Further studies are needed for examining the effect of global CVD calculation on actual patient outcomes. Communication among CVRPT stakeholders and health care policy makers in Egypt will help for guiding evidence based prevention of CVD. Adopting a clear, easy, simple, cost effective CVRPT as well as physician training will promote the utilization of CVR scores in clinical practice, and will guarantee an effective physician/patient partnership to improve patient outcomes.

\section{References}

1) WHO. Noncommunicable diseases and mental health. Country profiles 2011, Egypt. Available from: http://www. who.int/nmh/countries/egy_en.pdf

2) WHO. The global burden of disease: 2004 update. Geneva: World Health Organization; 2008.

3) Gaziano TA, Bitton A, Anand S, Abrahams-Gessel S, Murphy A.
Growing epidemic of coronary heart disease in low- and middle-income countries. Curr Probl Cardiol. 2010;35(2):72-115.

4) De Backer G, Ambrosioni E, Borch-Johnsen $\mathrm{K}$, Brotons $\mathrm{C}$, Cifkova R, Dallongeville J, Ebrahim S, Faergeman O, Graham I, Mancia G, Manger Cats V, Orth-Gomer K, Perk J, Pyorala K, Rodicio JL, Sans S, Sansoy V, Sechtem U, Silber S, Thomsen T, Wood D. European guidelines on cardiovascular disease prevention in clinical practice. Third Joint Task Force of European and Other Societies on Cardiovascular Disease Prevention in Clinical Practice. Eur Heart J. 2003;24:16011610.

5) Pearson TA, Blair SN, Daniels SR, Eckel RH, Fair JM, Fortmann SP, Franklin BA, Goldstein LB, Greenland P, Grundy SM, Hong Y, Miller NH, Lauer RM, Ockene IS, Sacco RL, Sallis JF Jr, Smith SC Jr, Stone NJ, Taubert KA. AHA guidelines for primary prevention of cardiovascular disease and stroke: 2002 update: Consensus panel guide to comprehensive risk reduction for adult patients without coronary or other atherosclerotic vascular diseases. American Heart Association science advisory and coordinating committee. Circulation. 2002;106(3):388-391.

6) Lloyd-Jones DM. Cardiovascular risk prediction: basic concepts, current status, and future directions. Circulation. 2010;121(15):1768-77.

7) WHO World Health Organization. The World Health Report 2003: 
shaping the future. Geneva: WHO;2003.

8) Abegunde DO, Shengelia B, Luyten A, Cameron A, Celletti F, Nishtar S, Pandurangi V, Mendis S. Can non-physician health-care workers assess and manage cardiovascular risk in primary care? Bull World Health Organ. 2007;85(6):432-40.

9) Rouham Yamout, Salim M Adib, Randa Hamadeh, Alia Freidi, Walid Ammar. Screening for cardiovascular risk in asymptomatic users of the primary health care network in Lebanon, 2012-2013.Prev Chronic Dis. 2014;11:140089.

10) Liew SM, Blacklock C, Hislop J, Glasziou P, Mant D. Cardiovascular risk scores: qualitative study of how primary care practitioners understand and use them. $\mathrm{Br} \mathrm{J}$ Gen Pract. 2013;63(611):e401-7.

11) Grover SA, Lowensteyn I. The challenges and benefits of cardiovascular risk assessment in clinical practice. Can J Cardiol. 2011;27(4):481-7.

12) Pandya A1, Weinstein MC, Salomon JA, Cutler D, Gaziano TA. Who needs laboratories and who needs statins?: comparative and costeffectiveness analyses of nonlaboratory-based, laboratory-based, and staged primary cardiovascular disease screening guidelines. Circ Cardiovasc Qual Outcomes. 2014;7(1):25-32.

13) Maniecka-Bryla I, MaciakAndrzejewska A, Bryła M, Bojar I. An assessment of health effects of a cardiological prophylaxis programme in a local community with the use of the SCORE algorithm. Ann Agric Environ Med. 2013;20(4):794-9.

14) Jackson R. Updated New Zealand cardiovascular disease risk-benefit prediction guide. $\mathrm{Br}$ Med $\mathrm{J}$. 2005;320:709-710.

15) Fonarow GC. A practical approach to reducing cardiovascular risk factors. Rev Cardiovasc Med. 2007;8 Suppl 4:S25-36

16) Hobbs FD, Erhardt L. Acceptance of guideline recommendations and perceived implementation of coronary heart disease prevention among primary care physicians in five European countries: the Reassessing European Attitudes about Cardiovascular Treatment (REACT) survey. Fam Pract. 2002;19: 596-604.

17) Mendis S. Cardiovascular Risk Assessment and Management in Developing Countries. Vasc Health Risk Manag. 2005;1(1):15-18.

18) Eichler K, Zoller M, Tschudi $P$, et al. Barriers to apply cardiovascular prediction rules in primary care: a postal survey. BMC Fam Pract. 2007;8(1):1-14.

19) Eichler $K, \quad B i l l e r-A n d o r n o \quad N$, Traindl O, Tschudi P, Bachmann LM, Steurer J. Cardiovascular prediction rules: problems for application in practice results of a workshop. Praxis (Bern 1994) 2006;95(45):1751-6.

20) Hobbs FD, Jukema JW, Da Silva PM, McCormack T, Catapano AL. Barriers to cardiovascular disease risk scoring and primary prevention in Europe. QJM. 2010;103(10):72739.

21) Persell SD, Zei C, Cameron KA, Zielinski M, Lloyd-Jones DM. Potential use of 10-year and lifetime coronary risk information for 
preventive cardiology prescribing decisions: A primary care physician survey. Arch Intern Med. 2010;170(5):470-477.

22) Kerlinger, F. N. (1973). Foundations of behavioral research. New York: Holt, Rinehart, and Winston, Inc.

23) Cooney MT, Dudina A, D'Agostino R, Graham IM. Cardiovascular risk-estimation systems in primary prevention: Do they differ? Do they make a difference? Can we see the future? Circulation 2010;122:300-10.

24) Doroodchi H, Abdolrasulnia M, Foster JA, Foster E, Turakhia MP, Skelding KA, Sagar K, Casebeer LL. Knowledge and attitudes of primary care physicians in the management of patients at risk for cardiovascular events. BMC FamPract. 2008;9:42.

25) Shillinglaw B, Viera AJ, Edwards T, Simpson R, Sheridan SL. Use of global coronary heart disease risk assessment in practice: a crosssectional survey of a sample of U.S. physicians. BMC Health Serv Res. 2012;12:20.

26) Schmieder RE, Goebel M, Bramlage P. Barriers to cardiovascular risk prevention and management in Germany--an analysis of the EURIKA study. Vasc Health Risk Manag. 2012;8:177-86.

27) Imms A1, Quinn S, Nelson $M$. General practitioners' use of cardiovascular risk calculators. Aust Fam Physician. 2010;39(1-2):57-60.

28) Hebatallah NE, Shaimaa AA, Gamila MN, Hassan AA. Global cardiovascular risk assessment by family physicians in Suez canal university-family medicine centersEgypt. JFMPC. 2013;2(4):365-70.

29) Sposito AC, Ramires JAF, Jukema JW, et al. Physicians' attitudes and adherence to use of risk scores for primary prevention of cardiovascular disease: cross-sectional survey in three world regions. Curr Med Res Opin. 2009;25:1171-8.

30) Jackson R, Lawes CM, Bennett DA, et al. Treatment with drugs to lower blood pressure and blood cholesterol based on an individual's absolute cardiovascular risk. Lancet. 2005; 365: 434-441.

31) Müller-Riemenschneider F1, Holmberg C, Rieckmann N, Kliems H, Rufer V, MüllerNordhorn J, Willich SN. Barriers to routine risk-score use for healthy primary care patients: survey and qualitative study. Arch Intern Med. 2010;170(8):719-24.

32) Sheridan SL, Viera AJ, Krantz MJ, et al. The effect of giving global coronary risk information to adults: A systematic review. Arch Intern Med. 2010;170(3):230-239.

33) D'Agostino RB Sr, Vasan RS, Pencina MJ, Wolf PA, Cobain M, Massaro JM, Kannel WB. General cardiovascular risk profile for use in primary care: the Framingham Heart Study. Circulation. 2008;117:743753.

34) Conroy RM, Pyorala K, Fitzgerald AP, Sans S, Menotti A, De Backer G, DeBacquer D, Ducimetiere $P$, Jousilahti P, Keil U, Njolstad I, Oganov RG, Thomsen T, TunstallPedoe H, Tverdal A, Wedel H, Whincup P, Wilhelmsen L, Graham IM. Estimation of ten-year risk of fatal cardiovascular disease in Europe: the SCORE project. Eur Heart J. 2003;24:987-1003. 
35) Woodward M, Brindle P, TunstallPedoe H. Adding social deprivation and family history to cardiovascular risk assessment: the ASSIGN score from the Scottish Heart Health Extended Cohort (SHHEC). Heart. 2007;93:172-176.

36) Hippisley-Cox J, Coupland C, Vinogradova Y, Robson J, Minhas R, Sheikh A, Brindle P. Predicting cardiovascular risk in England and Wales: prospective derivation and validation of QRISK2. BMJ. 2008;336:1475-1482.

37) Assmann G, Cullen P, Schulte H. Simple scoring scheme for calculating the risk of acute coronary events based on the 10-year followup of the Prospective Cardiovascular Münster (PROCAM) study. Circulation. 2002;105:310 -315.

38) Prevention of Cardiovascular Disease: Guidelines for Assessment and Management of Cardiovascular Risk. Geneva, Switzerland: World Health Organization; 2007.

39) Ridker PM, Buring JE, Rifai N, Cook NR. Development and validation of improved algorithms for the assessment of global cardiovascular risk in women: the Reynolds Risk Score. JAMA. 2007;297:611-619.

40) Ridker PM, Paynter NP, Rifai N, Gaziano JM, Cook NR. C-reactive protein and parental history improve global cardiovascular risk prediction: the Reynolds Risk Score for men. Circulation. 2008;118:2243-2251.

41) Liew S M , Doust J, Glasziou $P$ Cardiovascular risk scores do not account for the effect of treatment: a review. Heart. 2011;97:689-697.

42) Phillips LS, Branch WT Jr, Cook CB, Doyle JP, El-Kebbi IM, Gallina DL, Miller CD, Ziemer
DC, Barnes CS: Clinical Inertia. Ann Intern Med. 2001,135:825-834.

43) Cabana MD, Rand CS, Powe NR, Wu AW, Wilson MH, Abboud PA, Rubin HR: Why don't physicians follow clinical practice guidelines? A framework for improvement. JAMA 1999;282:1458-1465.

44) Christian AH, Mills T, Simpson SL, Mosca L: Quality of cardiovascular disease preventive care and physician/practice characteristics. J Gen Intern Med. 2006, 21:231-237.

45) Choudhry NK, Fletcher RH, Soumerai SB: Systematic review: the relationship between clinical experience and quality of health care. Ann Intern Med. 2005;142:260-273.

46) Kline, P. The handbook of psychological testing (2nd ed.). London: Routledge, 2000;page 13.

47) Explorable.com (May 2, 2009). Statistical Correlation. Retrieved Mar 29, 2015 from Explorable.com: https://explorable.com/statisticalcorrelation

48) van Steenkiste $B$, van der Weijden T, Stoffers HE, Grol R. Barriers to implementing cardiovascular risk tables in routine general practice. Scand J Prim Health Care. 2004;22:32-37.

49) Fretheim A, Oxman AD, Flottorp S. Improving prescribing of antihypertensive and cholesterollowering drugs: a method for identifying and addressing barriers to change. BMC Health Serv Res. 2004;4:23.

50) Parkin RT. Communications with research participants and communities: foundations for best practices. J Expo Anal Environ Epidemiol. 2004;14(7):516-23. 
51) Estimation of ten-year risk of fatal cardiovascular disease in Europe: the SCORE project European Heart Journal 2003;24:987-1003

52) Wilson PW, D'Agostino RB, Levy D, Belange AM, Silbershatz $\mathbf{H}$, Kannel WB. Prediction of coronary heart disease using risk factor categories. Circulation. 1998;97(18):1837-1847.

53) WHO. Prevention of cardiovascular disease: Pocket guidelines for assessment and management of cardiovascular risk. World Health Organization. 2007.

54) Reiner Z, Sonicki Z, TedeschiReiner E. Physicians' perception, knowledge and awareness of cardiovascular risk factors and adherence to prevention guidelines: the PERCRO-DOC survey. Atherosclerosis. 2010;213:598-603.

55) Webster R, Heeley E. Perceptions of risk: understanding cardiovascular disease. Risk Manag Health Policy. 2010;3:49-60.

56) Pollak KI, Krause KM, Yarnall KS, Gradison M, Michener JL, Ostbye T. Estimated time spent on preventive services by primary care physicians. BMC Health Serv Res. 2008;8:245.

57) Sheridan S, Pignone M, Mulrow C. Framingham-based tools to calculate the global risk of coronary heart disease: A systematic review of tools for clinicians. J Gen Intern Med. 2003;18(12):1039-105

58) Graham IM, Stewart M, Hertog MG. Cardiovascular Round Table Task Force. Factors impeding the implementation of cardiovascular prevention guidelines: Findings from a survey conducted by the European Society of Cardiology. Eur J Cardiovasc Prev Rehabil. 2006;13:839-45. 
Table I: Physicians' characteristics, their awareness, and their utilization of CVRPT

\begin{tabular}{|c|c|c|c|c|c|c|c|}
\hline \multirow[t]{2}{*}{$\begin{array}{l}\text { Physicians' } \\
\text { Characteristics }\end{array}$} & \multirow[t]{2}{*}{$\begin{array}{c}\text { (N=176) } \\
\text { n(\%) } \\
\text { (if not } \\
\text { stated } \\
\text { otherwise) }\end{array}$} & \multicolumn{2}{|c|}{$\begin{array}{c}\text { Often \& rarely use } \text { us* }_{\text {CVRPT }}\end{array}$} & \multicolumn{2}{|c|}{$\begin{array}{c}\text { Know the } \\
\text { difference between } \\
\text { CVRPT and } \\
\text { guidelines } \\
(\mathrm{N}=66)\end{array}$} & \multicolumn{2}{|c|}{$\begin{array}{c}\text { Know which } \\
\text { CVRPT to choose }\end{array}$} \\
\hline & & $\mathrm{n}(\%)$ & $\begin{array}{l}\text { Chi } \\
\text { square } \\
\text { (P-value) }\end{array}$ & $\mathrm{n}(\%)$ & $\begin{array}{l}\text { Chi } \\
\text { square } \\
\text { (P-value) }\end{array}$ & $\mathrm{n}(\%)$ & $\begin{array}{l}\text { Chi } \\
\text { square } \\
\text { (P-value) }\end{array}$ \\
\hline $\begin{array}{l}\text { Age }(\text { mean } \pm \text { SD) } \\
\text { - } 30 \text { years- } \\
\text { - } 45-55\end{array}$ & $\begin{array}{c}39.5 \pm 4.5 \\
152(86.4) \\
24(13.6)\end{array}$ & $\begin{array}{l}87(57) \\
12(50)\end{array}$ & $\begin{array}{c}0.46 \\
(0.49)\end{array}$ & $\begin{array}{c}60(69) \\
6(50)\end{array}$ & $\begin{array}{c}1.7 \\
(0.192)\end{array}$ & $\begin{array}{r}59(67.8) \\
8(66.7)\end{array}$ & $\begin{array}{l}\mathrm{F} \\
0.1\end{array}$ \\
\hline $\begin{array}{l}\text { Gender } \\
\text { - } \quad \text { Males } \\
\text { - } \quad \text { Females }\end{array}$ & $\begin{array}{l}102(58) \\
74(42)\end{array}$ & $\begin{array}{l}54(53) \\
45(61)\end{array}$ & $\begin{array}{c}1.08 \\
(0.298)\end{array}$ & $\begin{array}{l}38(65.5) \\
28(62)\end{array}$ & $\begin{array}{c}0.74 \\
(0.389)\end{array}$ & $\begin{array}{l}45(83.3) \\
22(48.8)\end{array}$ & $\begin{array}{c}9.14 \\
(0.002)^{*}\end{array}$ \\
\hline 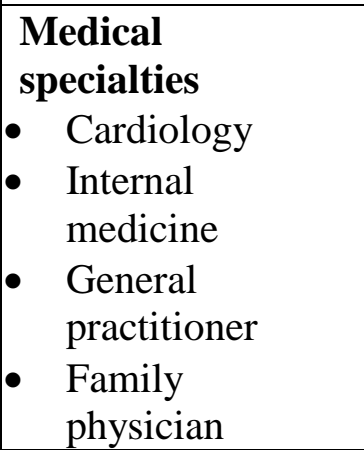 & $\begin{array}{l}18(10.2) \\
61(34.7) \\
57(32.4) \\
40(22.7)\end{array}$ & $\begin{array}{l}9(50) \\
29(47) \\
31(54) \\
30(75)\end{array}$ & $\begin{array}{c}7.938 \\
(0.047)^{*}\end{array}$ & $\begin{array}{c}6(66.7) \\
17(58.6) \\
23(74.2) \\
20(66.7)\end{array}$ & $\begin{array}{c}\mathrm{F} \\
(0.650)\end{array}$ & $\begin{array}{l}7(77.8) \\
15(51.7) \\
20(64.5) \\
25(83.3)\end{array}$ & $\begin{array}{c}\mathrm{F} \\
(0.088)\end{array}$ \\
\hline $\begin{array}{l}\text { Median of Years } \\
\text { since medical } \\
\text { license } \\
\text { - } \quad<10 \text { years } \\
\text { - } \geq 10 \text { years }\end{array}$ & $\begin{array}{l}152(86.4) \\
24(13.6)\end{array}$ & $\begin{array}{l}82(54) \\
17(70)\end{array}$ & $\begin{array}{c}3.02 \\
(0.082)\end{array}$ & $\begin{array}{l}53(64.6) \\
13(76.5)\end{array}$ & $\begin{array}{c}\mathrm{F} \\
(0.409)\end{array}$ & $\begin{array}{c}55(67) \\
12(70.5)\end{array}$ & $\begin{array}{c}\mathrm{F} \\
(0.1)\end{array}$ \\
\hline $\begin{array}{l}\text { Medical } \\
\text { certificates } \\
\text { - } \text { Diploma } \\
\text { - } \text { Master } \\
\text { - } \\
\text { Doctoral degree }\end{array}$ & $\begin{array}{c}85(48.3) \\
79(44.9) \\
12(6.8)\end{array}$ & $\begin{array}{c}55(64.7) \\
38(48) \\
6(50)\end{array}$ & $\begin{array}{c}4.01 \\
(0.134)\end{array}$ & $\begin{array}{l}32(58) \\
30(79) \\
4(66.7)\end{array}$ & $\begin{array}{c}\mathrm{F} \\
(0.093)\end{array}$ & $\begin{array}{c}40(72) \\
23(60.5) \\
4(66.7)\end{array}$ & $\begin{array}{c}\mathrm{F} \\
(0.469)\end{array}$ \\
\hline
\end{tabular}

$* *$ Often $\&$ rarely use $=$ once a week $\&$ once a month

* chi-square test is statistically significant at $95 \%$ confidence level $(P$-value $<0.05)$ 
Table II: Percentages of physicians' agreement for each retained question, questionnaire's reliability, and validity

\begin{tabular}{|c|c|c|c|c|c|}
\hline \multirow[t]{3}{*}{ Domains } & \multirow[t]{3}{*}{ Questions } & \multirow{3}{*}{$\begin{array}{l}\text { Median of } \\
\text { responses } \\
(\mathrm{N}=20 \\
\text { panelists })\end{array}$} & \multicolumn{3}{|c|}{$(\mathrm{N}=176)$} \\
\hline & & & \multicolumn{3}{|c|}{ Agree all the time, and most of the time } \\
\hline & & & $\begin{array}{l}\mathrm{n}(\%) \text { of } \\
\text { agreement }\end{array}$ & $\begin{array}{l}\text { Item total } \\
\text { correlation }\end{array}$ & $\boldsymbol{R}^{* *}$ \\
\hline Overall & $\begin{array}{l}\text { The results of prediction rules } \\
\text { are often not helpful for } \\
\text { decision making in practice* }\end{array}$ & 2 & - & - & - \\
\hline \multirow[t]{7}{*}{$\begin{array}{l}\text { Distrust in the } \\
\text { validity of } \\
\text { CVRPT }\end{array}$} & $\begin{array}{l}\text { A single risk score does not } \\
\text { take into account the complex } \\
\text { situation of the patient }\end{array}$ & 4 & $145(82)$ & .147 & \multirow{7}{*}{.586} \\
\hline & $\begin{array}{l}\text { you are not in need for the } \\
\text { CVRPT to estimate patients' } \\
\text { risk }\end{array}$ & 4.5 & $85(48)$ & .393 & \\
\hline & $\begin{array}{l}\text { Patients may have risk factors } \\
\text { that are not included in the } \\
\text { CVRPT }\end{array}$ & 4.5 & $138(78)$ & .220 & \\
\hline & $\begin{array}{l}\text { You depend on a single risk } \\
\text { factor for decision making } \\
\text { thus you know how to treat }\end{array}$ & 4 & $92(52)$ & .387 & \\
\hline & $\begin{array}{l}\text { CVRPT could not be applied } \\
\text { to all patients' groups }\end{array}$ & 4 & $116(65)$ & .504 & \\
\hline & $\begin{array}{l}\text { Patients with } \\
\text { cardiovascular risk may } \\
\text { develop angina or myocardial } \\
\text { infarction }\end{array}$ & 4.5 & $135(76)$ & .183 & \\
\hline & $\begin{array}{l}\text { You don't trust the "Percent } \\
\text { Risk" of having a cardiac } \\
\text { event as calculated by the } \\
\text { tool }\end{array}$ & 3.5 & $120(68)$ & .445 & \\
\hline \multirow[t]{3}{*}{$\begin{array}{l}\text { Distrust in } \\
\text { stakeholders }\end{array}$} & $\begin{array}{l}\text { Over treatment may occur } \\
\text { while applying the results of } \\
\text { these tools in treating patients }\end{array}$ & 3.5 & $122(69)$ & .246 & \multirow[t]{3}{*}{.331} \\
\hline & $\begin{array}{l}\text { You don't know which } \\
\text { stakeholders were involved in } \\
\text { the development of these } \\
\text { tools }\end{array}$ & 4 & $156(89)$ & .105 & \\
\hline & $\begin{array}{l}\text { The external control by health } \\
\text { authorities could lead to the } \\
\text { misuse of the CVRPT }\end{array}$ & 4 & $114(64)$ & .238 & \\
\hline
\end{tabular}




\begin{tabular}{|c|c|c|c|c|c|}
\hline \multirow[t]{4}{*}{$\begin{array}{l}\text { Aspects of } \\
\text { practicability }\end{array}$} & $\begin{array}{l}\text { Application of cardiovascular } \\
\text { risk assessment tools is time } \\
\text { consuming }\end{array}$ & 4.5 & $82(46)$ & .469 & \multirow[t]{3}{*}{.322} \\
\hline & $\begin{array}{l}\text { Patients may not want to know } \\
\text { their individual risk }\end{array}$ & 3.5 & $128(73)$ & .274 & \\
\hline & $\begin{array}{l}\text { Tools may depend on } \\
\text { investigations that patients } \\
\text { could not afford }\end{array}$ & 3.5 & $146(83)$ & .181 & \\
\hline & I have ethical concerns* & 2.5 & - & - & - \\
\hline \multirow[t]{3}{*}{$\begin{array}{l}\text { Distrust in the } \\
\text { concept of } \\
\text { prevention }\end{array}$} & $\begin{array}{l}\text { Risk assessment is of no use if } \\
\text { not accompanied by } \\
\text { preventive measures }\end{array}$ & 4 & $143(81)$ & .037 & \multirow[t]{3}{*}{.474} \\
\hline & $\begin{array}{l}\text { Total costs of the health care } \\
\text { system will not be reduced. }\end{array}$ & 4 & $115(65)$ & .284 & \\
\hline & \begin{tabular}{|lrr} 
Patients' & cardiac & risk \\
information & will & not \\
guarantee & for & their \\
compliance & & \\
\end{tabular} & 4.5 & $111(63)$ & .160 & \\
\hline
\end{tabular}

$*=$ omitted item, $* *=$ correlation co-efficient

Total Questionnaire $\mathrm{CC} \alpha=.78$ 
Table III: Physicians' regularity of using CVRPT, and their agreements on barriers against their utilization

\begin{tabular}{|c|c|c|c|c|c|c|}
\hline \multirow[t]{2}{*}{ Domains } & \multirow[t]{2}{*}{ Questions } & \multicolumn{3}{|c|}{$\begin{array}{l}\text { Regularity of using CVRPT } \\
\qquad(\mathrm{N}=176)\end{array}$} & \multirow{2}{*}{$\begin{array}{c}\text { Chi- } \\
\text { square } \\
\text { (P-value) }\end{array}$} & \multirow{2}{*}{$\begin{array}{c}\text { ANOVA } \\
\text { F } \\
\text { (P-value) }\end{array}$} \\
\hline & & $\begin{array}{l}\text { Often } \\
(\mathrm{N}=33)\end{array}$ & $\begin{array}{l}\text { Rarely } \\
(\mathrm{N}=66)\end{array}$ & $\begin{array}{l}\text { Never } \\
(\mathrm{N}=77)\end{array}$ & & \\
\hline \multirow{8}{*}{$\begin{array}{l}\text { 1- Distrust in the } \\
\text { validity of } \\
\text { CVRPT }\end{array}$} & $\begin{array}{l}\text { A single risk score does not take into account the complex } \\
\text { situation of the patient }\end{array}$ & 32 & 47 & 66 & $.004^{*}$ & \multirow{8}{*}{$\begin{array}{l}3.164 \\
(.045)^{\star}\end{array}$} \\
\hline & You are not in need for the CVRPT to estimate patients' risk & 17 & 36 & 32 & .121 & \\
\hline & $\begin{array}{l}\text { Patients may have risk factors that are not included in the } \\
\text { CVRPT }\end{array}$ & 30 & 47 & 61 & .068 & \\
\hline & $\begin{array}{l}\text { You depend on a single risk factor for decision making thus you } \\
\text { know how to treat }\end{array}$ & 21 & 33 & 38 & .256 & \\
\hline & CVRPT could not be applied to all patients' groups & 24 & 49 & 43 & $.024^{*}$ & \\
\hline & $\begin{array}{l}\text { Patients with low cardiovascular risk may develop angina or } \\
\text { myocardial infarction }\end{array}$ & 28 & 50 & 57 & .647 & \\
\hline & $\begin{array}{l}\text { You don't trust the "Percent Risk" of having a cardiac event as } \\
\text { calculated by the tool }\end{array}$ & 20 & 46 & 54 & .085 & \\
\hline & Mean (SD) & $13.9(3.2)$ & $15.2(2.3)$ & $15.1(2.6)$ & & \\
\hline \multirow[t]{4}{*}{$\begin{array}{l}\text { 2- Distrust in } \\
\text { stakeholders }\end{array}$} & $\begin{array}{l}\text { Over treatment may occur while applying the results of these } \\
\text { tools in treating patients }\end{array}$ & 22 & 45 & 55 & .314 & \multirow{4}{*}{$\begin{array}{l}1.399 \\
(.250)\end{array}$} \\
\hline & $\begin{array}{l}\text { You don't know which stakeholders were involved in the } \\
\text { development of these tools }\end{array}$ & 33 & 55 & 68 & $.022^{*}$ & \\
\hline & $\begin{array}{l}\text { The external control by health authorities could lead to the } \\
\text { misuse of the CVRPT }\end{array}$ & 19 & 45 & 50 & .712 & \\
\hline & Mean (SD) & $5.8(1.2)$ & $6(1.4)$ & $5.6(1.2)$ & & \\
\hline \multirow[t]{4}{*}{$\begin{array}{r}\text { 3- } \\
\text { pspects of } \\
\text { practicability }\end{array}$} & $\begin{array}{l}\text { Application of cardiovascular risk assessment tools is time } \\
\text { consuming }\end{array}$ & 13 & 37 & 32 & $.030^{\star}$ & \multirow{4}{*}{$\begin{array}{l}.832 \\
(.437)\end{array}$} \\
\hline & Patients may not want to know their individual risk & 24 & 51 & 53 & .229 & \\
\hline & Tools may depend on investigations that patients could not afford & 28 & 52 & 66 & .172 & \\
\hline & Mean (SD) & $6.5(1.2)$ & $6.3(1.5)$ & $6.5(1.2)$ & & \\
\hline \multirow{4}{*}{$\begin{array}{l}\text { 4- Distrust in } \\
\text { the concept of } \\
\text { prevention }\end{array}$} & $\begin{array}{l}\text { Risk assessment is of no use if not accompanied by preventive } \\
\text { measures }\end{array}$ & 24 & 54 & 65 & .100 & \multirow{4}{*}{$\begin{array}{l}1.662 \\
(.193)\end{array}$} \\
\hline & Total costs of the health care system will not be reduced & 24 & 37 & 54 & .173 & \\
\hline & $\begin{array}{l}\text { Patients' cardiac risk information will not guarantee for their } \\
\text { compliance }\end{array}$ & 25 & 43 & 43 & .216 & \\
\hline & Mean (SD) & $5.5(1.2)$ & $5.8(1.3)$ & $5.4(1.3)$ & & \\
\hline
\end{tabular}


Table IV: Barriers influencing the utilization of CVRPT as detected by stepwise forward conditional logistic regression

\begin{tabular}{|l|l|l|l|l|l|l|}
\hline Barriers & B & S.E. & Wald & df & P value & $\operatorname{Exp}(\mathbf{B})$ \\
\hline $\begin{array}{l}\text { - A single risk score does not take into } \\
\text { account the complex situation of the patient }\end{array}$ & 4.042 & 1.495 & 7.312 & 1 & $.007 *$ & 56.913 \\
\hline $\begin{array}{l}\text { - you don't know which stakeholders were } \\
\text { involved in the development of these tools }\end{array}$ & 1.849 & .776 & 5.675 & 1 & $.017 *$ & 6.356 \\
\hline Constant & 11.547 & 3.398 & 11.549 & 1 & .001 & 103508.458 \\
\hline
\end{tabular}

Barriers entered: "A single risk score does not take into account the complex situation of the patient", "CVRPT could not be applied to all patients' groups", "you don't know which stakeholders were involved in the development of these tools", and "application of cardiovascular risk assessment tools is time consuming". 